\title{
Development of LC-MS/MS confirmatory method for the determination of testosterone in bovine serum
}

\author{
Barbara Woźniak, Iwona Matraszek-Żuchowska, Sebastian Witek, Andrzej Posyniak \\ Department of Pharmacology and Toxicology \\ National Veterinary Research Institute, 24-100 Pulawy, Poland \\ bwozniak@piwet.pulawy.pl
}

Received: August 23, 2016 Accepted: March 10, 2017

\begin{abstract}
Introduction: In the European Union the use of steroid growth promoters is prohibited under Council Directive 96/22/EC. For effective control of illegal use of natural steroids, highly sensitive analytical methods are required, because sex hormones can be present in very low concentrations in biological samples. The aim of the study was to develop a confirmatory method for the detection of testosterone in bovine serum at ppt level. Material and Methods: $17 \beta$-testosterone and internal standards of $17 \beta$-testosterone-d2 were extracted from serum samples with a mixture of tert-butyl methyl ether/petroleum ether and were directly analysed by an LC/MS/MS on QTRAP 5500 instrument with a TurboIon-Spray source operating in a positive ionisation mode. Chromatographic separation was achieved on the analytical column Inertsil® ODS-3 with an isocratic elution using mobile phase consisting of acetonitrile, methanol, and water. Method validation has been carried out in accordance with the Commission Decision 2002/657/EC. Results: The method was characterised by good recovery (82\%) and precision (R.S.D $17 \%$ ). Decision limit $(\mathrm{CC} \alpha)$ and detection capability $(\mathrm{CC} \beta)$ was $0.05 \mu \mathrm{g} \mathrm{L}^{-1}$ and $0.09 \mu \mathrm{g} \mathrm{L}^{-1}$ respectively. The method met the criteria set out in Commission Decision 2002/657/EC for the purpose of confirmation in terms of retention time and ion ratio in the whole range of its application. Conclusions: The developed method is specific and sensitive, suitable for measuring the natural level of testosterone in blood of cattle and for use in routine control programme for the detection of this hormone in bovine serum.
\end{abstract}

Keywords: testosterone, bovine serum, validation, liquid chromatography, mass spectrometry.

\section{Introduction}

Testosterone $(\mathrm{T})$ is the primary male sex hormone, major androgen secreted by the testes of adult males. Androgens and oestrogens have a great impact on the functioning of the body of animals and humans. Natural sex hormones such as testosterone affect mainly the reproductive system, but they also act on metabolism and regulate and coordinate the activity of many organs and tissues of the body. In addition to the development of secondary sexual characteristics, testosterone has an anabolic effect, including increase in muscle size and strength and increase in lean body mass. These properties make it an attractive candidate for both athletes and breeders of slaughter animals to enhance performance. Therefore, testosterone or testosterone esters, alone or in combination with other hormonally active substances, have been widely used for many years in animal husbandry for the purpose of growth promotion (20). Testosterone is a component of such implants as Synovex-H and Component E-H available in the USA and Canada - countries that allow the use of hormones to improve the growth rate of slaughter animals and feed efficiency. In the European Union the use of steroid growth promoters is prohibited under Council Directive 96/22/EC, due to the possibility of harmful effects on public health (6). Control of the presence of these forbidden substances in food of animal origin and feed is regulated in the European Union under Directive 96/23/EC (7). Due to the high variability of natural testosterone concentration in the urine of cattle under physiological conditions, acceptable natural ranges of the hormone have not been established. A study by Angeletti et al. (1) demonstrated that the ratio between $17 \beta$-testosterone and $17 \alpha$-testosterone in urine cannot be used in bovine animals as an indicator for abuse as it is in human and horse. In 1992 Heitzman (13) proposed maximum levels of testosterone in bovine plasma depending on sex and age, and these values remained officially recommended until now. The threshold value of $0.5 \mu \mathrm{g} \mathrm{L}^{-1}$ for cows aged less than 18 months, $10 \mu \mathrm{g} \mathrm{L}^{-1}$ for male cattle below the age of 
6 months, and $30 \mu \mathrm{g} \mathrm{L}^{-1}$ for male cattle aged between 6 and 18 months, respectively, has been adopted. Thus, serum or plasma is the matrix of choice for the study of testosterone abuse. For effective control of illegal use of natural steroids, very sensitive analytical methods are required, because sex hormones may be present in very low concentrations in relatively small and complex biological samples.

For many years immunological methods based on the reaction of antigen-antibody, such as ELISA or RIA, have been widely used to determine the natural steroids in both human and veterinary medicine for screening purposes $(19,22)$. An important advantage of these methods is their sensitivity allowing detection of the hormone to picogram levels. In addition, these methods are very fast and efficient, and do not require expensive equipment. However, they may give false results, due to cross-reactivity with interfering compounds structurally similar to the analyte. Currently, chromatographic techniques with mass spectrometric detection play a major role in the analysis of the natural sex hormones in human and veterinary medicine, as well as in doping control, owing to their high selectivity and sensitivity. Therefore, many methods for the determination of testosterone based on different procedures using mass spectrometry have been published. In the method proposed by Savolainen et al. (23) testosterone was purified by the on-line SPE-column-switching technique after rapid precipitation of serum samples by zinc sulphate before LC-MS/MS analysis. A stable-isotope dilution LC-MS/MS method using atmospheric pressure photoionisation was established by Harwood and Handelsman (12) to quantify testosterone and other androgens and oestrogens. Sample preparation involved liquid-liquid extraction (LLE) with hexane: ethyl acetate containing deuterated internal standards. In human medicine on-line extraction and multiplexing before mass chromatography detection are used for testosterone level determination, to increase the sample throughput (24). Salameh et al. (21) developed a highly specific online mass spectrometry method in which sera were extracted online using high-turbulence flow liquid chromatography coupled to analytical HPLC and atmospheric pressure chemical ionisation tandem mass spectrometry (HTLC-APCI-MS/MS). The automated process of extraction, separation, and detection requires special equipment and large number of samples; therefore, these kinds of solutions cannot be used everywhere. Detection of endogenous steroids administration is still a challenge because classic mass spectrometric techniques are unable to distinguish between endogenous, exogenous, or synthetic forms of natural steroid hormones. At present, gas chromatography coupled to combustion/isotope ratio mass spectrometry (GC/C/IRMS) has emerged as a promising technique for demonstrating an abuse of exogenous homologues of natural steroid hormones in humans and cattle $(4,16)$. Currently the number of laboratories applying the GC/C/IRMS for routine analysis of bovine urine is very limited due to expensive equipment and difficulties associated with the analysis by this technique. Taking into account the threshold value for testosterone in bovine serum, the LC-MS/MS have sufficient sensitivity and accuracy to control the abuse, but not always are sensitive enough to measure the level of testosterone in the samples from the young animals, especially females. Therefore, new more sensitive methods based on mass spectrometry are needed.

The aim of the present study was to develop a confirmatory method for the quantitative detection and identification of testosterone in bovine serum at ppt levels. Because in recent years new opportunities associated with the preparation of biological samples have become available, this research focused on the preparation of serum samples before chromatographic analysis.

\section{Material and Methods}

Reagents and chemicals. All chemicals and reagents were of high grade purity. Petroleum ether, $30-60^{\circ} \mathrm{C}$ ultra resi-analysed for organic residue analysis, tert-butyl methyl (99.0\% purity), methanol (99.8\% purity), acetone (99.8\% purity) resin grade, methanol (99.8 \% purity) HPLC-MS grade, and acetonitrile (99.9\% purity) HPLC-MS grade were obtained from Mall Baker (the Netherlands). Formic acid reagent ( $\geq 95 \%$ purity) was obtained from Sigma-Aldrich (Germany). Purified water was prepared using a Milli-Q-water-purification system (Millipore, USA). Agilent Bond Elut QuEChERS extraction kits containing sorbents in the form of magnesium sulphate (6 $\mathrm{g}, 98.5 \%-101.5 \%$ purity) and sodium acetate (1.5 g, 99.8\% purity) were purchased from Agilent Technologies (Germany). Solid-phase extraction (SPE) columns Bakerbond $\mathrm{C}_{18} 500 \mathrm{mg} / 3 \mathrm{~mL}$ were provided by Mall Baker (the Netherlands). HybridSPE Phospholipid columns were purchased from Supelco (USA).

Standards of $17 \beta$-testosterone (98\% purity) and $17 \beta$-testosterone-d2 (95\% purity) were obtained from RIKILT (Institute of Food Safety, the Netherlands). The standards were stored in accordance with certificate recommendations. Individual hormone stock solutions of $10 \mu \mathrm{g} \mathrm{mL}^{-1}$ were prepared in methanol. A series of working solutions with concentrations of $1,0.1$, and $0.01 \mu \mathrm{g} \mathrm{mL}^{-1}$ were prepared by appropriate dilution of standard stock solutions with methanol. Stock standard solutions were kept in a freezer at temperature below $-18^{\circ} \mathrm{C}$; working standard solutions were stored at $4^{\circ} \mathrm{C} \pm 2^{\circ} \mathrm{C}$ and were stable for at least four weeks.

LC-MS/MS measurement. Analyses were carried out on Linear Ion Trap Quadrupole QTRAP 5500 mass spectrometer (Applied Biosystems/MDS SCIEX, Canada) fitted with Electrospray ionisation (ESI) Turbo Spray source operating in positive mode and controlled by analyst software (version 1.6)

The mass spectrometric conditions were optimised for maximum signal for 17 $\beta$-testosterone and 
$17 \beta$-testosterone-d2 using the tune feature of the instrument software. The optimal conditions of the instrument for testosterone were as follows: gas source temperature $-500^{\circ} \mathrm{C}$; ion spray voltage $-5300 \mathrm{~V}$; entrance potential - $10 \mathrm{~V}$; exit potential - $10 \mathrm{eV}$; curtain gas (nitrogen) - 20 psi; GS1 (air) - 20 psi; GS2 (air) - 25 psi; nebulizer gas (nitrogen) at medium position. Data were acquired in the mode of multiple reactions monitoring (MRM). The detailed conditions for MS detection of testosterone are shown in Table 1. The chromatographic separation was performed using 1200 HPLC binary pump system (Agilent Technologies, Germany) on an Inertsil ODS-3 $(150 \times 2.1 \mathrm{~mm}, 3 \mu \mathrm{m})$ (GL Sciences, Japan) with an octadecyl guard cartridge (4 mm $\times 2 \mathrm{~mm}$ ) (Phenomenex, USA). The column was maintained at a constant temperature of $35^{\circ} \mathrm{C}$. The mobile phase consisting of acetonitrile/methanol/water mixture (20:55:25, v/v) was pumped in isocratic mode with a total flow rate of $300 \mu \mathrm{L} \mathrm{min}{ }^{-1}$. The sample injection volume was $20 \mu \mathrm{L}$.

Optimisation of sample pre-treatment. Bovine serum contains natural sex steroids, including testosterone. Therefore, serum for the development and validation of the method was obtained from blood samples collected from one-month-old female calves. The collected serum samples were pooled and stored at $-18^{\circ} \mathrm{C}$ until analysis. Prior to use, the serum was examined by validated and accredited GC-MS method (30) in order to verify the presence of endogenous testosterone, which was not detected above decision limit of the method. Four sample preparation protocols were compared, each performed in four replicates. Tests were carried out on samples of serum $(2 \mathrm{ml})$ fortified with testosterone and testosterone-d2 (IS) to a concentration of $0.5 \mu \mathrm{g} \mathrm{L} \mathrm{L}^{-1}$.

SPE extraction. The fortified serum sample was diluted with $5 \mathrm{~mL}$ of water and loaded onto a SPE C18 cartridge $(300 \mathrm{mg}, 5 \mathrm{~mL}$ ) previously activated with $3 \mathrm{~mL}$ of methanol and then further conditioned with $3 \mathrm{~mL}$ of water. The column was washed with $3 \mathrm{~mL}$ of water and $3 \mathrm{~mL}$ of methanol/water mixture $(60: 40, \mathrm{v} / \mathrm{v})$. Then, $3 \mathrm{~mL}$ of methanol/water mixture $(80: 20, \mathrm{v} / \mathrm{v})$ was used as the elution agent. Finally, the eluate was evaporated under a stream of nitrogen at $60^{\circ} \mathrm{C}$ and reconstituted in $150 \mu \mathrm{L}$ of mobile phase consisting of a mixture of methanol/water $(70: 30, \mathrm{v} / \mathrm{v})$, then transferred to autosampler vials, and aliquots $(20 \mu \mathrm{L})$ were analysed by LC - MS/MS.
HybridSPE procedure. Sample of serum $(2 \mathrm{~mL})$ was prepared in accordance with the manufacturer's instructions (Supelco, USA). First, the precipitation step was performed by adding $6 \mathrm{~mL}$ of $1 \%$ formic acid in acetonitrile to the serum. After shaking stage lasting about $3 \mathrm{~min}$, the precipitated protein was removed by centrifugation at $1600 \times \mathrm{g}$ for $5 \mathrm{~min}$. The collected supernatant was loaded into the HybridSPE cartridge and vacuum was applied. The eluate was dried under a stream of nitrogen at $60^{\circ} \mathrm{C}$ and dissolved in $150 \mu \mathrm{L}$ of mobile phase consisting of methanol/water mixture (70:30, v/v).

QuEChERS extraction. Ten $\mathrm{mL}$ of acetonitrile measured off was added to a test tube containing $2 \mathrm{~mL}$ of serum, and the content was thoroughly mixed. Agilent QuEChERS extraction salts packet containing $6 \mathrm{~g}$ of magnesium sulphate and $1.5 \mathrm{~g}$ of sodium acetate was added directly to the tube. The mixture was then immediately shaken for $1 \mathrm{~min}$ using the vortex to avoid agglomeration of salts. The content of the tube was next centrifuged at $7728 \times \mathrm{g}$ for $10 \mathrm{~min}$ at $4^{\circ} \mathrm{C}$. The total acetonitrile extract was transferred to another glass tube and dried under a gentle stream of nitrogen at $60^{\circ} \mathrm{C}$ $\left( \pm 2^{\circ} \mathrm{C}\right)$. Finally, the residue was dissolved in $150 \mu \mathrm{L}$ of mobile phase methanol/water (70:30, v/v).

Liquid-liquid extraction (final protocol). Testosterone and IS were separated from the matrix $(2 \mathrm{~mL})$ by liquid-liquid extraction with $10 \mathrm{~mL}$ of a mixture of tert-butyl methyl ether/petroleum ether $(30: 70, \mathrm{v} / \mathrm{v})$ by shaking on a vortex for $3 \mathrm{~min}$. After separation phase, the tube was placed in a freezer at $<-18^{\circ} \mathrm{C}$ for $1.5-2 \mathrm{~h}$. The organic layer was then decanted into a glass tube and evaporated at $60^{\circ} \mathrm{C}\left( \pm 2^{\circ} \mathrm{C}\right)$ under a gentle stream of nitrogen. The residue was dissolved in $150 \mu \mathrm{L}$ of mobile phase consisting of methanol/water mixture (70:30, v/v), and then transferred to autosampler vials, and aliquots $(20 \mu \mathrm{L})$ were analysed by $\mathrm{LC}$ - MS/MS. In final protocol the mobile phase consisted of acetonitrile/methanol/water mixture (20:55:25, v/v). The efficiency of the methods was evaluated on the basis of extraction recovery expressed as the ratio of the response of sample with analyte to the response of postextracted spiked sample.

Validation. The developed method was submitted to the validation process in accordance with the general requirements of Commission Decision 2002/657/EC (5). The study was conducted using the ResVal (v 2.0) software (CRL Laboratory, the Netherlands) intended for validation of analytical methods (3).

Table 1. LC-MS/MS ion acquisition parameters (MRM) mode used for identification and confirmation of testosterone

\begin{tabular}{|c|c|c|c|c|c|c|}
\hline \multirow{2}{*}{ Compound } & \multirow{2}{*}{$\begin{array}{l}\text { MRM transition } \\
(\mathrm{m} / \mathrm{z})\end{array}$} & \multirow{2}{*}{$\begin{array}{l}\text { Collision energy } \\
(\mathrm{eV})\end{array}$} & \multirow{2}{*}{$\begin{array}{l}\text { Declustering } \\
\text { potential }(\mathrm{V})\end{array}$} & \multirow{2}{*}{$\begin{array}{l}\text { Ion ratio average } \\
\pm \mathrm{SD}\end{array}$} & \multicolumn{2}{|c|}{ Samples fulfilling confirmation criteria $(\%)$} \\
\hline & & & & & $0.25-30 \mu \mathrm{g} \mathrm{L}^{-1}$ & CC $\alpha$ level \\
\hline Testosterone & $\begin{array}{l}\mathbf{2 8 9 . 0}>97.0^{\mathbf{a}} \\
289.0>109.0\end{array}$ & $\begin{array}{l}29 \\
29\end{array}$ & $\begin{array}{l}110 \\
110\end{array}$ & $0.829 \pm 0.023$ & 100 & 100 \\
\hline Testosterone- $-\mathrm{d} 2$ & $\begin{array}{l}\mathbf{2 9 1 . 0}>\mathbf{9 9 . 0} \\
291.0>111.0\end{array}$ & $\begin{array}{l}30 \\
30\end{array}$ & $\begin{array}{l}110 \\
110\end{array}$ & - & - & - \\
\hline
\end{tabular}

${ }^{\mathrm{a}}$ Transitions in bold were used for quantification 
Linearity was tested in seven levels of the calibration of the analyte concentrations corresponding to $0-0.05-0.25-0.5-1.25-2.5$ and $15 \mu \mathrm{g} \mathrm{L} \mathrm{L}^{-1}$ in the sample. Linearity was assessed on the basis of four standard calibration curves. To estimate precision (repeatability and within-laboratory reproducibility), recovery, the decision limit $(\mathrm{CC} \alpha)$, and the detection capability $(\mathrm{CC} \beta)$ of the method, three analytical series consisting of 21 samples at five concentration levels were carried out on three separate days. Each series consisted of six replicate test portions, at fortification levels of $0.25,0.5$, and $0.75 \mu \mathrm{g} \mathrm{L}^{-1}$, and in addition, one sample of $1.0 \mu \mathrm{g} \mathrm{L}^{-1}$ and one of $2.5 \mu \mathrm{g} \mathrm{L}^{-1}$.

Based on these experiments, the matrix calibration curves were determined, which were used to calculate $\mathrm{CC} \alpha$ and $\mathrm{CC} \beta$ using ResVal software, according to the approach described in ISO/11843 2000 (15). The following equations were used: $\mathrm{CC} \alpha=\left(\left(\mathrm{y}_{\mathrm{a}}+2.33 \mathrm{STD}_{\mathrm{a}}\right)-\right.$ $\left.\left.\mathrm{y}_{\mathrm{a}}\right)\right) /$ slope, $\mathrm{CC} \beta=\left(\left(\mathrm{y}_{\mathrm{a}}+2.33 \mathrm{STD}_{\mathrm{a}}+1.64 \mathrm{STD}_{\mathrm{a}}\right)-\right.$ $\left.\mathrm{y}_{\mathrm{a}}\right)$ )/slope, where $\mathrm{y}_{\mathrm{a}}$ is the intercept of calibration curve, and $\operatorname{STD}_{\mathrm{a}}$ is the standard deviation of the $\mathrm{y}_{\mathrm{a}}$.

The specificity study was based on the analysis of 10 serum samples taken from different female calves. Samples were analysed in duplicate, at first fortified only with internal standard, and then fortified both with internal standard and the testosterone to a final concentration equivalent to $0.5 \mu \mathrm{g} \mathrm{L}^{-1}$. Furthermore, the interference study with structurally related steroids including $\alpha$-testosterone, 19-nortestosterone, boldenone, and methyltestosterone was performed. In addition, the experiment comprising twenty serum samples spiked at the estimated $\mathrm{CC} \alpha$ was conducted in order to demonstrate the effectiveness of the method at low levels of testosterone concentration. Given the expected concentration range, further performance of the method at $10 \mu \mathrm{g} \mathrm{L}^{-1}$ and $30 \mu \mathrm{g} \mathrm{L}^{-1}$ was checked, as well. For samples with concentration above $10 \mu \mathrm{g} \mathrm{L}{ }^{-1}$, the volume of the serum sample was reduced from $2 \mathrm{~mL}$ to $1 \mathrm{~mL}$.

To evaluate matrix effect occurrence, the difference between the mass spectrometric response for testosterone in the samples spiked after extraction and in solvent at the same concentration was investigated.

Quality assurance. Each time, at the start of LCMS/MS analysis, the standard and internal standard were injected to check the operating conditions of LCMS/MS equipment. For each analytical batch, calibration curve adjusted to a range of concentrations tested was prepared. The concentration of testosterone was calculated from the calibration curve by "internal standard technique" including the testosterone-d2 as internal standard. In each series of tests, spiked samples were analysed in order to verify the quality of the results. Identification of testosterone was based on the retention time in relation to the internal standard and the ion ratios of the product ions in accordance with Commission Decision 2002/657/ EC (5).

\section{Results}

The results for the optimisation of sample preparation are presented in Fig. 1. The best recovery and reproducibility were obtained when liquid-liquid extraction with a mixture of petroleum ether and tertbutyl methyl ether was used. For this procedure the recovery was $81 \%$ with reproducibility $8 \%$. For other methods used for sample preparation, the recovery of testosterone was lower and was 53\% for HybridSPE columns, $57 \%$ for SPE columns, and $61 \%$ for the QuEChERS technique.
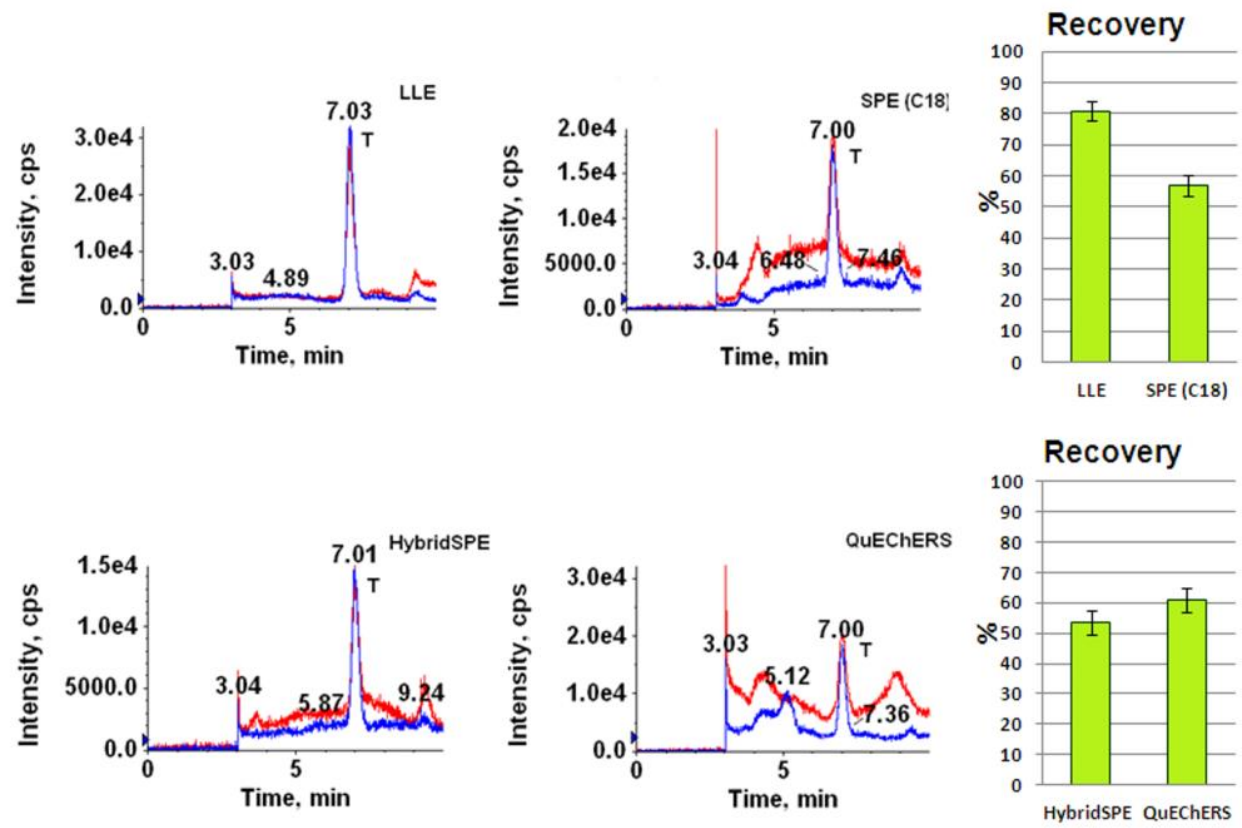

Fig. 1. LC-MS/MS chromatograms of bovine serum samples spiked with testosterone at $0.5 \mu g \mathrm{~L}^{-1}$ using different sample preparation protocols; recovery study 
Table 2. Results of the validation of method for the determination of testosterone in bovine serum samples

\begin{tabular}{|c|c|c|c|c|}
\hline Spiking level $\left(\mu \mathrm{g} \mathrm{L}^{-1}\right)$ & $\mathrm{n}$ & $\begin{array}{l}\text { Apparent recovery } \\
(\%)\end{array}$ & $\begin{array}{l}\text { Repeatability } \\
\text { (R.S.D., \%) }\end{array}$ & $\begin{array}{l}\text { Within-lab } \\
\text { reproducibility } \\
\text { (R.S.D., \%) }\end{array}$ \\
\hline 0.25 & 18 & 92.7 & 3.0 & 6.8 \\
\hline 0.5 & 18 & 93.0 & 5.7 & 15.2 \\
\hline 0.75 & 18 & 93.7 & 4.2 & 17.1 \\
\hline 10 & 6 & 82.3 & 9.1 & \\
\hline 30 & 6 & 91.5 & 4.7 & \\
\hline $0.05(\mathrm{CC} \alpha)$ & 20 & 116.4 & 16.1 & \\
\hline \multicolumn{2}{|c|}{ Decision limit $\left(\mathrm{CC} \alpha, \mu \mathrm{g} \mathrm{L}^{-1}\right)$} & 0.05 & & \\
\hline \multicolumn{2}{|c|}{ Detection capability $\left(\mathrm{CC} \beta, \mu \mathrm{g} \mathrm{L}^{-1}\right)$} & 0.08 & & \\
\hline \multicolumn{2}{|c|}{ Matrix effect $(\%)$} & 18.5 & & \\
\hline \multicolumn{2}{|c|}{$\begin{array}{l}\text { Measurement uncertainty at } 0.5 \mu \mathrm{g} \mathrm{L}^{-1}(\%) \\
(\mathrm{U}, \mathrm{k}=2)\end{array}$} & 30.0 & & \\
\hline \multicolumn{5}{|c|}{ Calibration curve } \\
\hline \multicolumn{2}{|l|}{ Slope $\pm S_{b}$} & \multicolumn{3}{|l|}{$1.9994 \pm 0.3282$} \\
\hline \multicolumn{2}{|l|}{$\mathrm{y}$-Intercept $\pm \mathrm{s}_{\mathrm{a}}$} & \multicolumn{3}{|l|}{$0.0017 \pm 0.168$} \\
\hline \multicolumn{2}{|l|}{ Correlation coefficient } & \multicolumn{3}{|l|}{0.9997} \\
\hline \multicolumn{5}{|l|}{ Matrix calibration curve } \\
\hline \multicolumn{2}{|l|}{ Slope $\pm \mathrm{s}_{\mathrm{b}}$} & \multicolumn{3}{|l|}{$1.8003 \pm 0.1232$} \\
\hline \multicolumn{2}{|l|}{$\mathrm{y}$-Intercept $\pm \mathrm{s}_{\mathrm{a}}$} & \multicolumn{3}{|l|}{$0.2536 \pm 0.1283$} \\
\hline \multicolumn{2}{|l|}{ Correlation coefficient } & \multicolumn{3}{|l|}{0.9978} \\
\hline
\end{tabular}
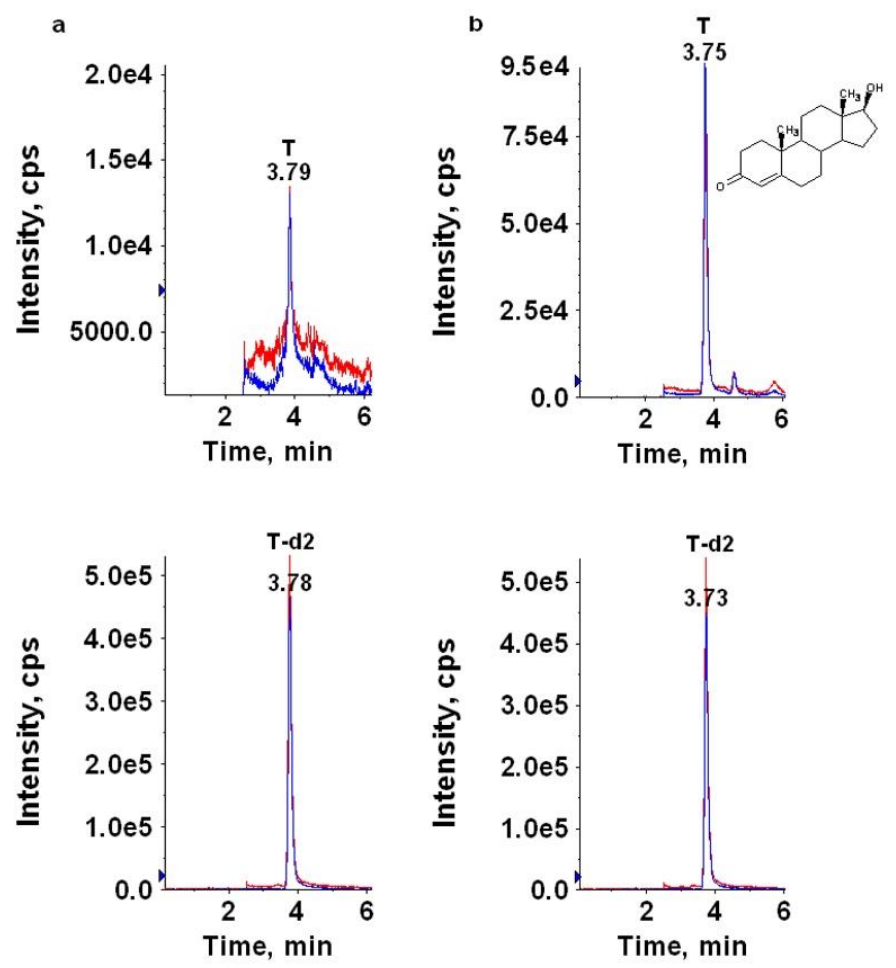

Fig. 2. LC-MS/MS chromatograms of: (a) a blank bovine serum sample endogenous $\mathrm{T}<\mathrm{CC} \alpha$, (b) a spiked bovine serum sample testosterone at 0.05 $\mu \mathrm{g} \mathrm{L}-1(\mathrm{CC} \alpha)$

A summary of the results of validation for 17 $\beta$-testosterone is presented in Table 2. The developed method is characterised by a good apparent recovery and precision. Recovery corrected using the internal standard exceeds 90\%, repeatability expressed as relative standard deviation does not exceed $17 \%$, and within-laboratory reproducibility is $18 \%$, for the entire range of the method. The designated $\mathrm{CC} \alpha$ and $\mathrm{CC} \beta$ for testosterone are much lower than the current value of $0.5 \mu \mathrm{g} \mathrm{L}-1$ of the proposed recommended concentration for female bovine and amounting to $0.05 \mu \mathrm{g} \mathrm{L}^{-1}$ and $0.08 \mu \mathrm{g} \mathrm{L}^{-1}$ respectively. The calculated correlation coefficients for the standard calibration curve and for the matrixmatched calibration curve exceeded 0.99 , thus ensuring good linearity of the method in the range of concentrations tested. Examination of matrix 
interferences using blank matrix samples, samples spiked with testosterone and samples fortified with structurally similar steroids showed no peaks in the area of retention time of analyte; therefore, the method has proved to be specific for testosterone.

The relative intensities of ions determined during the validation and presented in Table 1 evidence that the presence of testosterone was confirmed in all fortified samples in accordance with the criteria laid down in Council Decision 2002/657 / EC (5).

Examples of LC-MS/MS chromatograms of blank matrix serum sample and serum sample spiked to a concentration of $0.05 \mu \mathrm{g} \mathrm{L}^{-1}$ are shown in Figs $2 \mathrm{a}$ and $2 b$.

\section{Discussion}

The first stage of development of the analytical procedure was to optimise the condition for the detection of testosterone. Acquisition parameters for the mass spectrometer were optimised by a direct continuous pump infusion of working standard solutions of testosterone and testosterone-d 2 at a concentration of $5 \mu \mathrm{g} \mathrm{mL}^{-1}$ in the electrospray source. Positive ionisation mode was applied according to previous work done in the laboratory (31) and based on the literature (27). The collection of data was conducted initially in a full scan to select the abundant precursor ion $(\mathrm{M}+\mathrm{H})+$. Finally, analyses were performed by multiple reactions monitoring mode, which allows obtaining a higher specificity and sensitivity of the detection process. Major ions produced in MS and MS/MS have been identified and selected, then the mass spectrometer parameters were optimised to increase the sensitivity. Precursor-product transitions for testosterone as well as the corresponding collision energies are shown in Table 1. For testosterone, two MRM transitions were monitored. The most sensitive ion was used to quantify and the other to confirm it in order to meet the criteria required for the confirmatory methods in accordance with Commission Decision 2002/657/EC (5). The chromatographic separation of testosterone was carried out on a C18 Inertsil ODS-3 $(150 \times 2.1 \mathrm{~mm}, 3 \mu \mathrm{m})$ column. To obtain the best results, various compositions of the mobile phase, flow rate of mobile phase, and column temperature were checked. In preliminary chromatographic separation of testosterone, a mobile phase of methanol/water $(70: 30, \mathrm{v} / \mathrm{v})$ and a flow rate of $0.300 \mathrm{~mL}$ $\mathrm{min}^{-1}$ were tested. After using a mobile phase consisting of acetonitrile/methanol/water $(20: 55: 25, \mathrm{v} / \mathrm{v})$ at $35^{\circ} \mathrm{C}$ and with the same flow rate, the time of analysis was reduced from 7 min to less than 4 min.

In residue studies, in addition to the appropriate techniques of detection, no less important is the proper preparation of the sample. It is essential to use repeatable sample preparation procedures in order to minimise the differences between the samples in the course of analysis. Quantitative determination of the steroids may be hindered due to the simultaneous extraction of other endogenous matrix components that are typically present in much higher concentrations in the matrix than the analytes of interest. In the current research, four protocols for the preparation of bovine serum were evaluated for their suitability for the determination of testosterone by LC-MS/MS: solid phase extraction (SPE) using two types of columns, QuEChERS technique, and liquid-liquid extraction. Reversed-phase SPE devices are the most popular devices for the separation of analytes from biological matrices, due to the significant reduction in the consumption of organic solvents, concentration of the extract, improvement of repeatability, reduction in analysis time, simplicity, and safety. The application of solid phase extraction with C18 columns for isolation of testosterone from bovine serum samples with standard approach to this type of SPE sorbent allowed obtaining recovery of $57 \%$ with a CV equal to $21 \%$.

A method alternative to the traditional SPE is HybridSPE-Phospholipid Technology, intended for treatment of either serum or plasma samples prior to LC-MS/MS analysis, and allowing the simultaneous removal of proteins and phospholipids from the samples. Recovery and precision of the extraction of testosterone from bovine serum after applying HybdridSPE columns were similar to those obtained using C18 columns and amounted to $53 \%$ and $20 \%$, respectively. Taking into account the current trends in the preparation of biological samples, the QuEChERS technique was also tested. In this case testosterone was extracted from serum with acetonitrile and following the addition of the salts, analytes and matrix components were divided into aqueous and organic phases. For that method of sample preparation the recovery of testosterone was over $60 \%$ and the CV was slightly lower than $20 \%$.

Finally, a mixture of petroleum ether and tert-butyl methyl ether (30:70, v/v) was applied, because it was expected that the selected non-polar solvent should be effective for the isolation of moderately polar compounds of such steroids from aqueous samples. Recovery of testosterone exceeded $80 \%$ with a relative standard deviation of $8 \%$. On the basis of the recovery and precision obtained it was found that the application of LLE is sufficient for the proper detection of testosterone in a sample. The extract obtained was pure and most of the compounds, including phospholipids that cause ion suppression/interference, were removed. The extraction process is relatively fast and the solvents used are inexpensive, making it an attractive option for high-throughput analysis. Thus, in this case the goldstandard tool such as LLE was more effective for purification of biological samples than other novelties. During the study of steroids in samples of animal origin, several different purification steps must often be used to achieve the desired degree of cleanup. The most popular methods for the separation of natural hormones involve several steps, such as a liquid - liquid extraction, further purification on a SPE column $(9,10)$, immunoaffinity 
columns (28), or combinations thereof. However, it is known that each additional extraction step which is being used causes loss of precision and recovery of the method. Because the losses in precision are additive, the final relative standard deviation of the process may be substantial (10). Thus, finally a simple LLE procedure has been selected for preparation of serum samples prior to LC-MS/MS analysis. A small number of stages of the procedure eliminates the problems associated with the recovery and shortens the sample preparation time. In addition, an internal standard used in this method reduced all the variation and losses during sample preparation before instrumental analysis. Moreover, the application of the stable isotope-labelled internal standard is one way to compensate the matrix effect (14). Matrix effect (ME), such as enhancement or suppression of analytical signal frequently occurs in the chemical analysis of biological samples measured by LC-MS/MS (2). This is related to the alteration in ionisation efficiency in the ionisation source due to the presence of co-eluting, in particular endogenous substances present in the sample and remaining in the final extract. Type of ionisation source strongly influences the $\mathrm{ME}$ phenomenon. Atmospheric pressure chemical ionisation (APCI) is considered to be less matrix-dependent than electrospray ionisation (ESI). The consequence of this phenomenon is first of all a reduction in the signal increase of the analyte and adverse effect on linearity, repeatability, accuracy of the method, and ion ratio. Different assessment methods of the ME have been presented in the scientific literature such as the postcolumn infusion (2), comparison of the calibration curves (18) and the post-extraction spiking method (17). In our study we used the last-mentioned method. Noticeable signal suppression observed for testosterone in serum samples was $40.2 \%$. Deuterated internal standard did compensate for the observed ion suppression and relative matrix effect was $18.5 \%$. According to the criteria used by some authors, the range between $-20 \%$ and $20 \%$ is considered as no matrix effect, because this variation is similar to repeatability (11).

Although the LC-MS/MS is characterised by a high selectivity compared to other mass spectrometry techniques, the specificity of the method was demonstrated by analysis of the different blank bovine serum samples and, in parallel, the same samples fortified with testosterone at $0.5 \mu \mathrm{g} \mathrm{L}^{-1}$. No interference for each transition around the retention time of testosterone was observed. Because testosterone is an endogenous hormone, it is present in each sample, and thus the chromatogram shows small peak derived from testosterone, but a corresponding concentration is much lower than the decision limit of the method. Specificity studies with structurally similar steroids showed no interfering peaks in terms of the retention time of testosterone, therefore the method has proved to be specific for this androgenic compound.
The linearity of the chromatographic response of testosterone was checked throughout the range of tested concentrations. Calibration curve for the detection of target compound was obtained by performing a linear regression analysis of the standard solution by using the ratio of standard area to internal standard area against analyte concentrations. Good linearity was achieved for testosterone as indicated by the values of the correlation coefficients $\left(r^{2}\right)$ exceeding 0.99 .

Since the certified reference materials are not available, trueness has been assessed as the recovery calculated on the basis of fortified serum samples. The average recovery is very satisfactory, ranging from $82.3 \%$ to $116.4 \%$ at every level of fortification. Precision of the method is also valid as evidenced by within-laboratory reproducibility that does not exceed $18 \%$. These parameters were found to be satisfactory, in terms of accounting requirements of Commission Decision 2002/657/EC (5).

The determined values of $\mathrm{CC} \alpha$ and $\mathrm{CC} \beta$ were significantly lower than currently recommended concentration for testosterone, established at $0.5 \mu \mathrm{g} \mathrm{L}^{-1}$ (8). To test the effectiveness of the method in the range of the lowest concentration, the analysis of 20 serum samples fortified at $\mathrm{CC} \alpha$ was performed. The presence of testosterone was revealed in all samples, as shown in Table 2; moreover, good precision and recoveries at this level of concentration were achieved. The $\mathrm{CC} \alpha$ values obtained provide reliable determination at a level much below the actual recommended concentration for testosterone. Compared with the results presented by other authors using LC-MS/MS, the detection limits obtained are approximately the same $(19,29)$. The lower limit of detection of testosterone in human serum $\left(0.005 \mu \mathrm{g} \mathrm{L}^{-1}\right)$ was reported by Yamashita et al. (32) after application of picolinic acid for derivatisation of testosterone before the LC-MS/MS analysis. Highly sensitive approach based on GC-MS/MS technique and specific derivatisation with (pentafluorobenzyl)hydroxylamine $\mathrm{HCl}$ and MSTFA was developed by Thakur et al. (25), allowing to achieve the limit of quantification of testosterone equal to $0.00025 \mu \mathrm{g} \mathrm{L}^{-1}$ in human serum.

Because the method is designed for the purpose of confirmation, the criteria specified in the Commission Decision 2002/657/EC for quantitative confirmatory methods were checked during validation. The method fulfils the criteria set out in Commission Decision 2002/657/EC for the purpose of confirmation in terms of retention time and ion ratio in the whole range of its application (5). On the basis of the results obtained in validation studies, uncertainty of measurement was estimated for testosterone at the level of $0.5 \mu \mathrm{g} \mathrm{L}^{-1}$. When estimating the uncertainty, reproducibility and repeatability resulting from the matrix effect were primarily taken into account. The combined uncertainty was multiplied by a coverage factor of 2 to estimate expanded uncertainty which was $30 \%$. A slightly lower 
value for testosterone uncertainty determined in human serum by LC-MS / MS has been reported by Turpeinen et al. (26), but other authors have presented similar or higher values for hormones in biological matrices (31).

The LC-MS/MS method developed for the detection and confirmation of $17 \beta$-testosterone in bovine serum is highly sensitive and capable of quantitative determination of low circulating levels of this endogenous androgen. Due to the simple procedure of sample preparation, short LC-MSMS running time, high specificity and sensitivity, this method is suitable for use in routine control programme for the detection of testosterone in bovine serum from both sexes and research on the occurrence of endogenous testosterone.

Conflict of Interests Statement: The authors declare that there is no conflict of interests regarding the publication of this article.

Financial Disclosure Statement: This work was supported by the Polish Ministry of Agriculture and Rural Development.

Animal Rights Statement: None required.

\section{References}

1. Angeletti R., Contiero L., Gallina G., Montesissa C.: The urinary ratio of testosterone to epitetosterone: a good marker of illegal treatment also in cattle? Vet Res Comm 2006, 30, 127-131.

2. Antignac J.P., De Wasch K., Monteau F., De Brabander H., Andre F., Le Bizec B.: The ion suppression phenomenon in liquid chromatography-mass spectrometry and its consequences in the field of residue analysis. Anal Chim Acta 2005, 529, 129-136.

3. ARO SOP $475 B$, Method validation using ResVal ${ }^{\circledR}$. Validation according to EC/2002/657. National Institute of Public Health and Environment - RIVM, the Netherlands 2004, 1-17.

4. Bulska E., Gorczyca D., Zalewska I., Pokrywka A., Kwiatkowska D.: Analytical approach for the determination of steroid profile of humans by gas chromatography isotope ratio mass spectrometry aimed at distinguishing between endogenous and exogenous steroids: J Pharmaceut Biomed 2015, 106, 159-166.

5. Commission Decision 2002/657/EC (2002) of $12^{\text {th }}$ August 2002 implementing Council Directive 96/23/EC concerning the performance of analytical methods and the interpretation of results. Off J Eur Commun 2002, L 221, 8-36.

6. Council Directive 96/22/EC of 29 April 1996, concerning the prohibition of use in stock farming of certain substances having a hormonal or thyreostatic action and of $\beta$-agonists, and repealing directives 81/602/EEC, 88/146/EEC and 88/299/EEC. Off J Eur Commun1996, L125, 3-9.

7. Council Directive 96/23/EC of 29 April 1996, on measures to monitor certain substances and residues thereof in live animals and animal products. Off J Eur Commun 1996, L125, 10-32.

8. CRL Guidance Paper, CRLs view on state of the art analytical methods for national residue control plans. December 2007. http://www.rivm.nl/bibliotheek/digitaaldepot/crlguidance2007.pdf.

9. Draisci R., Palleschi L., Ferretti E., Lucentini L., Cammarata P.J.: Quantitation of anabolic hormones and their metabolite in bovine serum and urine by liquid chromatography - tandem mass spectrometry. J Chromatogr A 2000, 870, 511-522.

10. Fedeniuk R.W., Boison J.O., MacNeil J.D.: Validation of gas chromatography-mass spectrometry method for the determination of $\mathrm{pg} / \mathrm{mL}$ levels of $17 \beta$-estradiol and $17 \beta$-trenbolone in bovine serum. J Chromatogr B 2004, 802, 307-315.

11. Ferrer C., Lozano A., Agüera A., Girón A. J., Fernández-Alba A.R.: Overcoming matrix effects using the dilution approach in multiresidue methods for fruits and vegetables. J Chromatogr A, 2011, 1218, 7634-7639.

12. Harwood D.T., David J., Handelsman D.J.: Development and validation of a sensitive liquid chromatography-tandem mass spectrometry assay to simultaneously measure androgens and estrogens in serum without derivatization. Clin Chim Acta 2009, 409, 78-84.

13. Heitzman R.J.: Residues in food-producing animals and their products: Reference materials and methods. CEC, report EUR 14126EN, 1992

14. Hewavitharana A.K.: Matrix matching in liquid chromatographymass spectrometry with stable isotope labelled internal standardsis it necessary? J Chromatogr A 2011, 1218, 359-361.

15. ISO/11843: Capability of Detection (Part 1): Terms and Definitions (Part 2) 2000: Methodology in the Linear Calibration Case.

16. Janssens G., Courtheyn D., Mangelinckx S., Prévost S., Bichon E., Monteau F., De Poorter G., De Kimpe N., Le Bizec B.: Use of isotope ratio mass spectrometry to differentiate between endogenous steroids and synthetic homologues in cattle: a review. Anal Chim Acta 2013, 772, 1-15.

17. Matuszewski B.K., Constanzer M.L., Chavez-Eng C.M. Strategies for the assessment of matrix effect in quantitative bioanalytical methods based on HPLC-MS/MS. Anal Chem 2003, 75, 3019-3030.

18. Matuszewski B.K.: Standard line slopes as a measure of a relative matrix effect in quantitative HPLC-MS bioanalysis. J Chromatogr B 2006, 830, 293-300.

19. Moal V., Mathieu E., Reynier P., Malthièry Y., Gallois Y.: Low serum testosterone assayed by liquid chromatography-tandem mass spectrometry. Comparison with five immunoassay techniques. Clin Chim Acta 2007, 386, 12-19.

20. Montgomery T.H., Dew P.F., and Brown M.S.: Optimizing carcass value and the use of anabolic implants in beef cattle. J Anim Sci 2001, 79, E296-E306

21. Salameh W.A, Redor-Goldman M.M, Clarke N.J., Reitz R.E., Caulfield M.P.: Validation of a total testosterone assay using highturbulence liquid chromatography tandem mass spectrometry: Total and free testosterone reference ranges. Steroids 2010, 75, 169-175.

22. Sangalang G.B., Freeman H.C.: A new sensitive and precise method for determining testosterone and 11-ketotestosterone in fish plasma by radioimmunoassay. Gen Comp Endocrinol 1977, 32, 432-439.

23. Savolainen K., Kiimamaa R., Halonen T.: High-throughput analysis of testosterone in serum samples by on-line solid phase extraction liquid chromatography-tandem mass spectrometry. Clin Chem Lab Med 2011, 49, 1845-1848.

24. Singh R.J.: Validation of a high throughput method for serum/plasma testosterone using liquid chromatography tandem mass spectrometry (LC-MS/MS). Steroids 2008, 73, 1339-1344.

25. Thakur R.A., Williard C., Rajasekaran A.: Using GC-MS/MS for superior sensitivity, specificity and precision in free testosterone analysis. Chromatography Today 2010, August/September, $22-24$.

26. Turpeinen U., Linko S., Itkonen O., Hämäläinen E.: Determination of testosterone in serum by liquid chromatographytandem mass spectrometry. Scand J Clin Lab Invest 2008, 68 , 50-57.

27. Vanhaecke L., Vanden Bussche J., Wille K., Bekaert K., De Brabander H.F.: Ultra-high performance liquid chromatography-tandem mass spectrometry in high-throughput confirmation and quantification of 34 anabolic steroids in bovine muscle. Anal Chim Acta 2011, 700, 70-77.

28. Wang S., Lin S., Du L., Zhuang H.: Flow injection chemiluminescence immunoassay for $17 \beta$-estradiol using an 
immunoaffinity column. Anal Bioanal Chem 2006, 384, 11861190.

29. Wooding K.M., Hankin J.A., Johnson C.A., Chosich J.D., Baek S.W., Bradford A.P., Murphy R.C., Santoro N.: Measurement of estradiol, estrone, and testosterone in postmenopausal human serum by isotope dilution liquid chromatography tandem mass spectrometry without derivatization. Steroids 2015, 96, 89-94.

30. Woźniak B., Matraszek-Żuchowska I., Żmudzki J.: Determination of $17 \beta$-oestradiol and testosterone in bovine serum with gas chromatography-mass spectrometry. Bull Vet Inst Pulawy 2011, $55,755-759$
31. Wozniak B., Matraszek-Zuchowska I., Zmudzki J.: LC-MS/MS fast analysis of androgenic steroids in urine. Anal Bioanal Chem 2012, 403, 2965-2972.

32. Yamashita K., Miyashiro Y., Maekubo H., Okuyama M., Honma S., Takahashi M., Numazawa M.: Development of highly sensitive quantification method for testosterone and dihydrotestosterone in human serum and prostate tissue by liquid chromatographyelectrospray ionization tandem mass spectrometry. Steroids 2009, 74, 920-926. 